\title{
Candesartan cilexetil in the treatment of chronic heart failure
}

\author{
Jean-Philippe Baguet \\ Gilles Barone-Rochette \\ Yannick Neuder \\ Department of Cardiology, University \\ Hospital, 38043 Grenoble, France
}

\begin{abstract}
The prevalence of heart failure is ever increasing around the world, particularly due to aging populations. Despite improvements in treatment over the last 20 years, the prognosis for heart failure remains poor. Among the treatments recommended for chronic heart failure, angiotensin-converting enzyme (ACE) inhibitors and beta-blockers are crucial, provided of course that they are not contraindicated. However, angiotensin II receptor blockers (ARBs) can also be a beneficial treatment option. Candesartan is a particular ARB, characterized by a strong binding affinity to the angiotensin II type 1 receptor and slow dissociation. The benefits of candesartan have been demonstrated by the CHARM programme, which showed that candesartan significantly reduces the incidence of cardiovascular death, hospital admissions for decompensated heart failure, and all-cause mortality in chronic heart failure patients with altered left ventricular systolic function, when added to standard therapies or as an alternative to ACE inhibitors when these are poorly tolerated. Furthermore, candesartan can protect against myocardial infarction, atrial fibrillation and diabetes. Tolerance to candesartan is good, but blood pressure and serum potassium and creatinine levels must be monitored.

Keywords: chronic heart failure, angiotensin II receptor blockers, candesartan, left ventricular systolic function
\end{abstract}

\section{Introduction}

Heart failure (HF) is a major public health issue. Indeed, it is increasingly prevalent around the world, particularly among men, in an ageing global population. ${ }^{1,2}$ Despite marked improvements in treatment over the last few decades, prognosis remains poor with significant morbidity (functional impairment, successive hospitalizations) and high mortality rates. ${ }^{3}$ The deaths occur not only at the acute stage, such as after cardiogenic shock following a myocardial infarction (MI), but also during the chronic stage.

Once HF is diagnosed, its characteristics need to be specified: is it left, right or both HF? Acute or chronic HF? HF with decreased or preserved left ventricular (LV) systolic function? The latter condition is defined by the existence of both HF and an LV ejection fraction (LVEF) of $>50 \%{ }^{4}$ It is important to point out at this stage that most clinical trials have been carried out on HF patients with LV systolic dysfunction. The etiology of HF must consistently be investigated, as treatment partly depends on the disease causing it. HF has many causes, the most frequent being ischemic heart disease and hypertension. ${ }^{5,6}$ When HF occurs in a patient, the triggering factors must be identified. These can include myocardial ischemia, infection, rhythm disturbances such as atrial fibrillation (AF) and conduction disturbances, blood pressure rises, poor treatment compliance and lifestyle and dietary habits.

\section{Chronic heart failure}

Chronic HF is defined as chronic inadequate performance of the heart. In fact, the progressive nature of HF can be explained by a complex combination of structural, 
functional, and biological changes to the heart. In the 2008 guidelines of the European Society of Cardiology for the diagnosis and treatment of acute and chronic HF, HF is defined as: "clinical syndrome in which patients have the following features: symptoms typical of HF, signs typical of $\mathrm{HF}$, and objective evidence of a structural or functional abnormality of the heart at rest." ${ }^{16} \mathrm{HF}$ is therefore diagnosed through a medical interview, a clinical examination and some other complementary tests (ECG, chest X-ray, B-type natriuretic peptide [BNP] and echocardiography).

\section{Treating chronic heart failure Drug treatment}

The best treatment for HF is primary prevention. However, despite considerable improvements in the treatment of cardiovascular risk factors, HF incidence is increasing. Primarily, treatment involves drugs as well as making and strictly following certain lifestyle and dietary changes (fluid restriction, weight monitoring, nutrition and exercise training).

At the acute stage, treatment consists of loop diuretics for fluid retention, inotropic agents for hypotension, oxygen therapy, non-invasive ventilation, antiarrhythmics, (amiodarone) for supraventricular or ventricular rhythm disturbances, antihypertensives (nitrites) for severe hypertension, antibiotics for infections and even accelerating the heart rate for excessive bradycardia. There are yet more devices and treatments available, but describing these is not the objective of this review. Of course, at the acute stage, it is imperative to treat the triggering factor (eg, coronary angioplasty, treating pneumonia or giving a transfusion for severe anemia).

During the chronic stage, HF can be treated with several categories of drugs, some of which have been assessed in large clinical trials, and others which have long been used empirically such as loop diuretics (for symptoms or signs of pulmonary or systemic venous congestion) and digoxin (for AF or symptomatic HF associated with an LVEF $<40 \%){ }^{6}$ Four main therapeutic categories are currently used in chronic HF treatment: beta-blockers, angiotensin-converting enzyme (ACE) inhibitors, aldosterone antagonists and angiotensin II type 1 receptor blockers (ARBs). We will not discuss mechanical treatments for HF such as cardiac resynchronization therapy (biventricular pacing), ventricular assist device, artificial heart and heart transplantation.

\section{Beta-blockers}

After having initially been contraindicated in cases of $\mathrm{HF}$, they are now among the essential drugs for the medical treatment of chronic HF. Indeed, not only do they improve symptoms but they reduce the frequency of HF recurrence and lower the mortality rate connected to this disease. ${ }^{7,8,9}$ For this indication, the approved beta-blockers are carvedilol, bisoprolol, metoprolol and nebivolol. Dosage must be gradually increased until the evidence-based target dose is reached or maximal tolerated dose.

\section{ACE inhibitors}

The efficacy of ACE inhibitors on the symptoms of HF, on tolerance of exercise and quality of life, as well as upon cardiovascular morbidity and mortality has been demonstrated. ${ }^{10,11,12}$ This beneficial action is particularly noticeable in cases of reduced LVEF, which can be partially reversed with this treatment (it acts upon LV remodeling). Therefore, according to the latest European recommendations on the treatment of chronic HF, an ACE inhibitor should be used, unless contraindicated or not tolerated, in all patients with symptomatic HF and an LVEF $\leq 40 \%{ }^{6}$

\section{Aldosterone antagonists}

Several studies have shown the beneficial role of certain aldosterone antagonists in chronic HF patients. Spironolactone (for all causes of HF) and eplerenone (for HF after MI) can therefore be used in addition to standard therapy in cases of LV systolic dysfunction ( $\mathrm{LVEF}<35 \%-40 \%$ ), to reduce cardiovascular morbidity and mortality linked to HF as well as sudden death. ${ }^{13,14}$ The latest ESC recommendations suggest adding a low-dose aldosterone antagonist to the treatment of HF patients with an LVEF $\leq 35 \%$ and severe symptomatic $\mathrm{HF}$, in the absence of hyperkalemia and significant renal dysfunction. ${ }^{6}$

\section{Angiotensin receptor blockers}

ARBs are an effective treatment against the harmful effects of the activation of the renin-angiotensin-aldosterone system (RAAS), which occur during hypertension or diabetes for example. ${ }^{15,16,17,18}$ The RAAS is also involved in the physiopathology of HF, and for this reason, the effect of ARBs has been studied in chronic HF sufferers.

The first clinical trial involving ARBs in the treatment of chronic HF was the ELITE study (Evaluation of Losartan In The Elderly), published in 1997, on a population of 722 patients aged over 65 suffering from HF with LV systolic dysfunction (LVEF $\leq 40 \%) .{ }^{19}$ Its objective was to determine whether losartan offers safety and efficacy advantages in the treatment of HF over ACE inhibition with captopril. In this study, losartan was generally better tolerated than captopril. Moreover, treatment with losartan was associated with an 
unexpected lower mortality rate than that found with captopril. In order to confirm losartan's advantage over captopril in terms of increased survival rates and tolerance, the investigators of the ELITE study then carried out the ELITE II study among 3152 patients aged over 60 with NYHA class II-IV HF and LVEF $\leq 40 \% .^{20}$ There were no significant differences in all-cause mortality or sudden death or resuscitated arrests between the two treatment groups. These results are all the more so disappointing since the ELITE II study raised the possibility of a negative outcome in chronic HF patients when losartan is combined with a beta-blocker.

The Val-HeFT trial (Valsartan Heart Failure Trial) was carried out among 5010 subjects with LV systolic dysfunction ( $\mathrm{LVEF}<40 \%$ ). ${ }^{21}$ Its objective was to evaluate the long-term effects of the addition of valsartan to standard therapy (including an ACE inhibitor in 93\% of patients and a beta-blocker in 35\%) for HF. Although mortality rates were identical with both valsartan and the placebo, the combined endpoint (cardiovascular morbidity and mortality) was significantly reduced $(-13 \%, \mathrm{p}=0.009)$ in the valsartan group, predominantly because fewer patients were hospitalized for HF (a $24 \%$ reduction in HF hospital admissions). It must be mentioned that this study revealed an increase in cardiovascular morbidity and mortality in patients who received the triple combination of an ACE inhibitor, a beta-blocker and valsartan. Following the release of this information, international recommendations on the treatment of HF discouraged RAAS blockade using this triple therapy approach. These guidelines were then modified following the release of the results of the CHARM programme. ${ }^{6}$

Several studies have shown the beneficial action of ACE inhibitors after an MI, particularly in cases of HF with LV systolic dysfunction. ${ }^{22,23,24}$ The advantage of ARBs in these conditions, either alone or in conjunction with an ACE inhibitor, was analyzed in the VALIANT study (Valsartan in Acute Myocardial Infarction). ${ }^{25}$ This study involved 14,703 patients who had recently presented an MI and who had presented signs of HF (either clinical or on X-ray examination) or an LVEF $\leq 35 \%-40 \%$, or both. After a 25-month follow-up period, the conclusions showed valsartan to be as effective as captopril within this population but that combining valsartan with captopril increased the rate of adverse events without improving survival.

Generally speaking, almost half of HF patients have an LVEF of at least $45 \%$. Patients are typically elderly and hypertensive. There is no established management strategy in such cases and it is logical to consider using RAAS blockers, ARBs in particular. The first large study to have provided some indications in this context is the CHARM-Preserved study which will be discussed later in this review. ${ }^{26}$ The I-Preserve study (Irbesartan in heart failure with Preserved ejection fraction) has just been published. ${ }^{27}$ This is a study involving 4128 subjects aged $60+$ with NYHA class II, III or IV and an LVEF $>45 \%$. After a 49-month follow-up period, during which the patients received irbesartan $(300 \mathrm{mg})$ or a placebo as well as the standard therapy ( $45 \%$ received an ACE inhibitor during the study), all-cause mortality rates and hospitalization rates for cardiovascular causes were identical in the two treatment groups (36\% versus $37 \%$ ).

\section{Candesartan in chronic HF}

Candesartan cilexetil is an ARB that is characterized by the strongest binding affinity to the angiotensin II type 1 receptor and its slow dissociation. ${ }^{28}$ It was first used in the treatment of hypertension. In this indication, the molecule is particularly well tolerated. ${ }^{29}$ Candesartan has subsequently been used in chronic HF. Experimental studies have shown that, in rats, long-term angiotensin II type 1 receptor blockade by candesartan prevented the development of diastolic HF through attenuation of LV relaxation abnormality and myocardial stiffening. ${ }^{30}$

\section{HF with LV systolic dysfunction}

The RESOLVD study (Randomized Evaluation of Strategies for Left Ventricular Dysfunction) This study demonstrated that a combination of candesartan (4 or $8 \mathrm{mg}$ ) and ramipril $(20 \mathrm{mg})$ had a positive effet on hemodynamic parameters, LV remodeling and neurohormonal activity in 768 patients with an LVEF $<40 \%$ and a 6-minute walk distance $<500$ meters. ${ }^{31}$ A post-hoc analysis of this study revealed that the patients who benefited the most from the candesartan plus ramipril combination were those who also received a beta-blocker (metoprolol). ${ }^{32}$

\section{The CHARM-Added trial}

The CHARM (Candesartan in Heart failure: Assessment of Reduction in Mortality and morbidity) was a programme of clinical trials designed to address a large spectrum of symptomatic HF patients (Figure 1). It involved three distinct trials running in parallel: randomized double-blind comparisons of candesartan to placebo. Each trial in the CHARM programme was independently designed to determine whether the addition of candesartan (from 4 to $8 \mathrm{mg}$ daily to $32 \mathrm{mg}$ daily) to other HF therapies would reduce the risk of cardiovascular death or hospital admissions for chronic HF. The CHARM programme included a total of 7601 patients with chronic HF overall. 


\section{CHARM programme}

(Candesartan vs placebo in chronic $\mathrm{HF}, \mathrm{N}=7599$ )

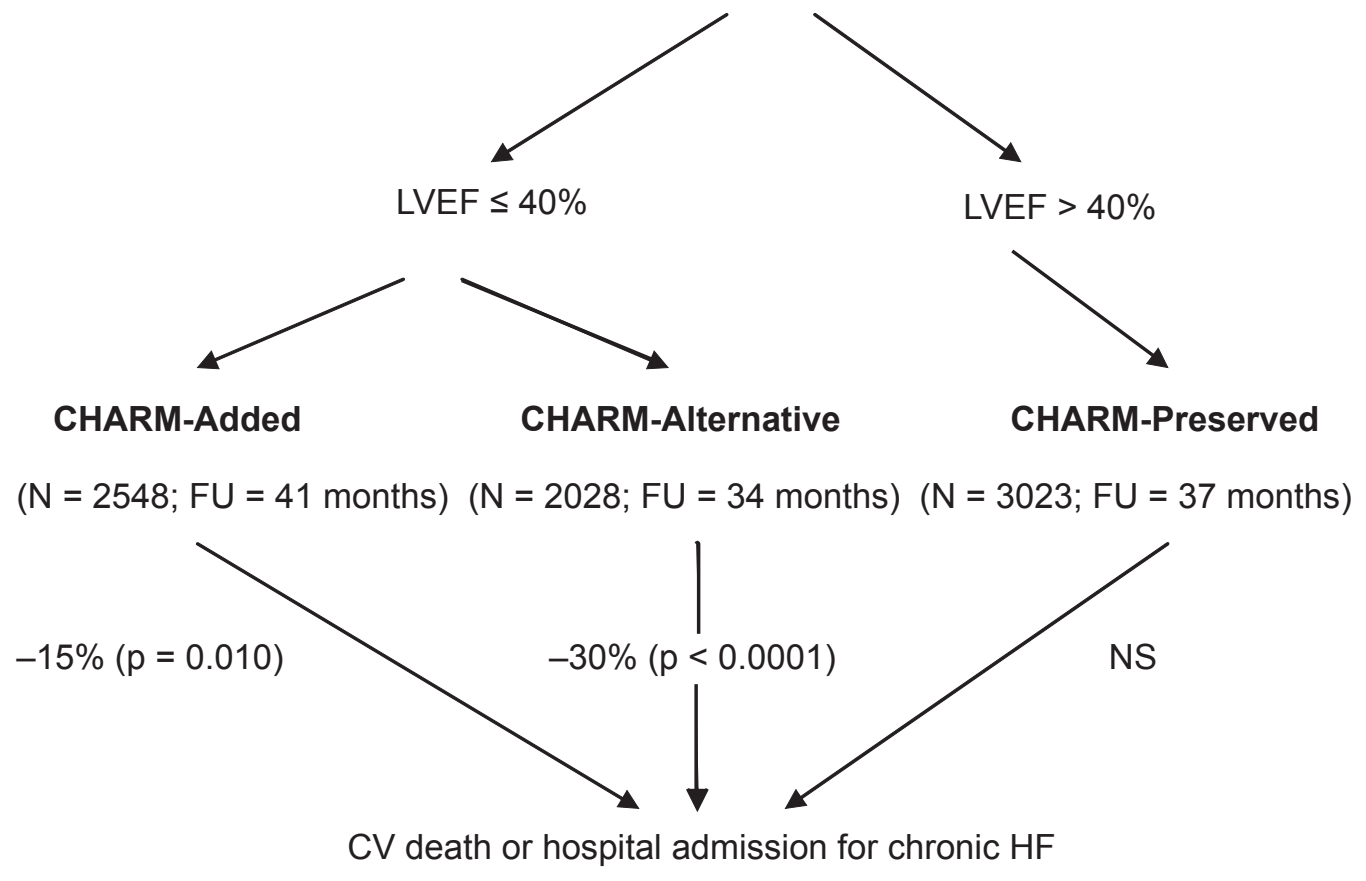

Figure I Diagram of the CHARM programme and its main results.

Abbreviations: CV, cardiovascular; FU, follow-up; HF, heart failure; LVEF, left ventricular ejection fraction; NS, non-significant.

We know that RAAS plays a major role during chronic HF. It therefore seems justifiable to attempt to block this neurohormonal system as effectively as possible in order to optimise the treatment of this disease. This blocking action can be achieved with an ACE inhibitor, an ARB or even a combination of the two. With this in mind, the CHARMAdded trial enrolled 2548 patients with an LVEF $\leq 40 \%{ }^{33}$ Not only were they all being treated with an ACE inhibitor but the majority of them (55\%) were also receiving a beta-blocker and a significant number $(17 \%)$ were receiving spironolactone. These patients were therefore already well-treated for their chronic HF. During the 41-month follow-up period, the group receiving candesartan presented fewer cases of cardiovascular death and hospital admissions for chronic HF (primary outcome) than the placebo group ( $15 \%$ reduction, $p=0.010)$. Moreover, each of the components of this primary outcome was reduced by candesartan. We can therefore conclude that the candesartan plus ACE inhibitor combination is beneficial in the treatment of chronic HF with reduced LVEF.

A more recent study also using candesartan but on a smaller scale than CHARM-Added was carried out on patients with chronic and stable HF with an LVEF $<40 \%{ }^{34}$ It was carried out on 80 subjects who had had at least
3 months of optimal, stable ACE inhibitor and beta-blocker treatment. In this study, too, the results concerning the ACE inhibitor plus candesartan combination are encouraging, as the NT-proBNP was $20 \%$ lower after 6 months with the combined treatment whereas it increased by $12 \%$ during the same period with ACE inhibitor alone. There is therefore a real advantage to carrying out a triple neurohumoral blockade in chronic HF patients with low LVEF. This blockade has a greater effect on LV remodeling and LVEF.

\section{The CHARM-Alternative trial}

A significant number of patients are ACE inhibitor-intolerant. Given the fact that blocking RAAS is vital in chronic HF patients, considering alternative treatment with ARBs was therefore justifiable. To study this, the CHARMAlternative trial was carried out among 2028 ACE inhibitorintolerant patients (presenting a cough, hypotension, or renal dysfunction) with an LVEF $\leq 40 \% \cdot{ }^{35}$ At the end of the 34-month follow-up period, this study demonstrated that there were fewer cases of cardiovascular deaths and hospital admissions for chronic HF in the active treatment group than in the placebo group (30\% reduction after adjustment, $\mathrm{p}<0.0001$ ), moreover with good ARB tolerance. 
The CHARM-Alternative trial therefore demonstrated that candesartan can be an effective and safe alternative to ACE inhibitors if these are not tolerated by a chronic HF patient.

The effect of candesartan in patients with chronic HF and LV systolic dysfunction has been studied in a CHARM programme patient sub-group (CHARM-Added or CHARMAlternative) which had LVEF $\leq 40 \%(\mathrm{~N}=4576) .{ }^{36}$ After a median follow-up period of 40 months, a $12 \%$ decrease in all-cause mortality ( $p=0.018$ ), a $16 \%$ decrease in cardiovascular mortality $(\mathrm{p}=0.005)$ and a $24 \%$ decrease in HF hospitalizations $(p<0.001)$ was observed in patients who received candesartan. In this study, the positive effects of candesartan treatment appeared early on, after as little as 1 year of treatment, regardless of other treatments taken at the same time (ACE inhibitors in $56 \%$ of patients, beta-blockers in $55 \%$, aldosterone antagonists in $20 \%$ ).

\section{HF with preserved LV systolic function The CHARM-Preserved trial}

The management strategy to be taken for chronic HF with preserved LVEF is not as clearly established as in cases of LV systolic dysfunction. It was therefore important to carry out a study in order to try to answer the following question: is an ARB a useful drug in the treatment of chronic HF with preserved LVEF? With this in mind, the CHARM-Preserved trial was carried out among 3023 patients with chronic HF, with NYHA functional class II-IV and LVEF $>40 \%{ }^{26}$ At the end of 37 months of follow-up, the administration of candesartan in conjunction with the standard therapy (beta-blockers for 56\% and ACE inhibitors for 20\%) had a positive impact ( $16 \%$ reduction, $p=0.047)$ versus placebo upon hospitalizations for $\mathrm{HF}$, but its effect on cardiovascular deaths was insignificant. In comparison to those obtained in the I-Preserve study, ${ }^{27}$ these results are positive. This could be partly explained by the difference in LVEF (mean LVEF $54 \%$ versus $59 \%$ in the CHARM-Preserved and I-Preserve studies respectively) and BNP levels in the two studies. The CHARM-Preserved trial, however, does not enable us to conclude that adding an ARB provides any significant improvement to the cardiovascular morbidity and mortality associated with chronic HF with preserved LVEF. In this specific situation, the 2008 ESC guidelines recommend an adequate treatment of hypertension and myocardial ischemia along ventricular rate control in patients with $\mathrm{AF}{ }^{6}$

\section{Candesartan and myocardial infarction}

Several studies have shown that ACE inhibitors reduce the risk of $\mathrm{MI}$ in patients with or without HF. ${ }^{22,23,24,37}$ However, it was not proven, until the results of the CHARM study came out, that a similar effect was recognized for ARBs in HF patients. During the 38-month follow-up period, the primary outcome of cardiovascular death and non-fatal MI was significantly reduced with candesartan $(-13 \%, \mathrm{p}=0.004) .{ }^{38}$ It is important to point out that $53 \%(\mathrm{~N}=4004)$ of the patients included had already experienced an MI and that $41 \%$ of them received an ACE inhibitor at baseline. The MI rate was similar in the group receiving the ACE inhibitor plus candesartan combination and the candesartan only group. In the same study, candesartan enabled the risk of non-fatal MI to be significantly reduced $(-23 \%, \mathrm{p}=0.03)$. Candesartan therefore seems to have a beneficial effect, independent of ACE inhibition, on the incidence of MI in HF patients.

\section{Candesartan and atrial fibrillation}

$\mathrm{AF}$ is a common condition in chronic HF patients. This arrhythmia can be both a cause and a consequence of cardiomyopathy, and can trigger systemic emboli. It is therefore important to ensure that it occur as late as possible or preferably not at all in chronic HF patients. Some experimental and clinical studies have shown that certain RAAS blockers could prevent AF from occurring. In the Val-HeFT study, taking valsartan decreased the incidence of AF in patients with reduced LVEF. ${ }^{39}$ The CHARM programme studied the effect of candesartan on the incidence of $\mathrm{AF}$ in a large cohort of patients (41\% receiving an ACE inhibitor at baseline) with symptomatic chronic HF and decreased or preserved LVEF. ${ }^{40}$ Among the 6,379 patients (84\%) without AF on their baseline electrocardiogram, 392 (6\%) developed AF during follow-up. Interestingly, there were fewer cases of AF with candesartan than with placebo $(-20 \%, p=0.039)$. Candesartan therefore seems potentially beneficial in the prevention of AF during chronic HF.

\section{The protective role of candesartan in the treatment of diabetes}

Diabetes is a significant cardiovascular risk factor which causes a high number of MIs. Similarly, it is a significant cause of chronic or acute HF. Moreover, diabetes causes myocardial lesions through various mechanisms, for example by leading to structural anomalies in extracellular matrix protein and the development of interstitial fibrosis. ${ }^{41}$ It is therefore important to treat this disease, whether type 1 or type 2 diabetes, both for primary and secondary prevention of coronary and/or myocardial events.

Another approach is the prevention of the onset of diabetes, by making dietary and lifestyle changes or by 
taking certain drugs. Among the latter, RAAS blockers are predominantly used. . $^{42,43,44}$ The effect of candesartan on the incidence of new diabetes cases was studied in the CHARM programme among 5436 non-diabetic HF patients out of the 7601 enrolled, whether they had a decreased LVEF or not. ${ }^{45}$ In this study, candesartan decreased the incidence of new diabetes cases by $22 \%$ compared to placebo (6.0 versus $7.4 \%, p=0.02$ ). This benefit appeared to be smaller in those receiving a concomitant $\mathrm{ACE}$ inhibitor compared with those who were not. This positive effect can in part be explained by the fact that angiotensin II is involved in the development of adipose tissue and that it modifies the response of certain cytokines to insulin.

In a study carried out among HF patients already being treated with an ACE inhibitor and a beta-blocker, adding candesartan decreased blood glucose to a greater extent in subjects with poorer glycemic control. ${ }^{34}$ In this study, further analyzes of insulin and fasting insulin resistance index suggest that candesartan is likely to improve glycemic control by increasing insulin release and also by improving insulin sensitivity.

\section{Candesartan and inflammation}

Patients with decompensated or compensated HF exhibit systemic inflammation, believed to be caused by the increase in hsCRP. In the Val-HeFT study, no significant changes in CRP were observed in patients already being treated with an ACE inhibitor with or without a beta-blocker. ${ }^{46}$ Conversely, White et al demonstrated that adding candesartan to an ACE inhibitor plus beta-blocker combination significantly decreased ( $-20 \%$ versus $+5 \%$ on placebo) plasma levels of hsCRP after six months of treatment. ${ }^{34}$

\section{Quality of life and tolerance of candesartan}

Importantly, in terms of the quality of life of HF patients, the addition of candesartan to conventional treatment significantly improves NYHA class compared to placebo. ${ }^{47}$ However, this positive effect was not detected in the CHARM preserved trial, which is probably a reflection of the low proportion of patients in NYHA class III/IV (39\%) in this trial compared to the two low LVEF trials (53\% in CHARM alternative and $76 \%$ in CHARM added).

In the Young et al study, adding candesartan to standard therapy (including ACE inhibitors) was shown to cause more side effects $(\mathrm{p}<0.001)$ than placebo, particularly increased plasma creatinine levels ( $7.1 \%$ versus $3.5 \%)$, hypotension (4.2\% versus $2.1 \%)$ and hyperkalemia $(2.8 \%$ versus $0.5 \%) .{ }^{36}$
During the CHARM trial, the authors observed an increased risk of hyperkalemia (ie, kalemia $\geq 5.0 \mathrm{mmol} / \mathrm{L}$ ), with $5.2 \%$ prevalence in the candesartan group versus $1.8 \%$ in the placebo group. ${ }^{48}$ The risk of hyperkalemia increased with the following factors: age $\geq 75$ years, male gender, diabetes, creatinine $\geq 2.0 \mathrm{mg} / \mathrm{dL}, \mathrm{K}+\geq 5.0 \mathrm{mmol} / \mathrm{L}$ at baseline, and background use of ACE inhibitors or spironolactone. However, in the CHARM-Alternative trial, study-drug discontinuation rates were similar in the candesartan $(30 \%)$ and placebo (29\%) groups. ${ }^{35}$ Moreover, the relative risk of discontinuation of candesartan (compared to placebo) because of hypotension, increased serum creatinine or hyperkalemia was not increased in patients taking the triple association of an ACE inhibitor plus spironolactone plus candesartan. ${ }^{49}$

A recent substudy of the CHARM programme was performed to assess the role of age on the efficacy and safety of candesartan. ${ }^{50}$ In this study, the risk of cardiovascular death or hospitalization for HF increased from $24 \%$ in the lowest age group to $46 \%$ in the highest (and mortality from $13 \%$ to $42 \%$ ). Interestingly, the absolute benefit of candesartan treatment was greater the older the patient, without an increase in adverse effects in the oldest patients. It is however essential to keep a close watch on serum potassium and creatinine levels when monitoring patients on candesartan, particularly when combined with an ACE inhibitor and/or spironolactone.

\section{Conclusions}

As recommended by the 2008 ESC guidelines on HF: "Unless contraindicated or not tolerated, an ARB is recommended in patients with $\mathrm{HF}$ and an $\mathrm{LVEF} \leq 40 \%$ who remain symptomatic despite optimal treatment with an ACE inhibitor and beta-blocker, unless they are also taking an aldosterone antagonist." The ARB candesartan significantly reduces cardiovascular death, hospital admission for decompensated $\mathrm{HF}$, and all-cause mortality in chronic HF patients with $\mathrm{LVEF} \leq 40 \%$, when added to standard therapies including ACE inhibitors, beta-blockers, and an aldosterone antagonist, or a combination of these. On the other hand, in patients with HF and preserved LVEF, adding candesartan does not provide any significant improvement to the cardiovascular morbi-mortality. In cases of ACE inhibitor-intolerance, candesartan is a safe and effective alternative. Candesartan also has a protective effect against incidence of MI, AF and diabetes (Table 1). Although candesartan tolerance is generally good, monitoring of blood pressure, and serum creatinine and potassium is warranted. This approach allows 
Table I Effects of candesartan during chronic heart failure

\section{Clinical effects}

- $\downarrow$ blood pressure

- $\downarrow$ new diabetes cases

- $\quad \downarrow$ atrial fibrillation

- $\downarrow$ myocardial infarctions

- $\downarrow$ CV death and hospitalizations for HF if LVEF $\leq 40 \%$

- $\quad \downarrow$ hospitalizations for HF if LVEF $>40 \%$

- $\uparrow$ quality of life

\section{Biological/Structural effects}

- $\downarrow$ neurohormonal activity (RAAS, BNP)

- Improved blood sugar levels

- $\downarrow$ systemic inflammation (hsCRP)

- Improved LV remodeling, $\uparrow$ LVEF

Abbreviations: BNP, b-type natriuretic peptide; $\mathrm{CV}$, cardiovascular; $\mathrm{HF}$, heart failure hsCRP, high-sensitivity c-reactive protein; LVEF, left ventricular ejection fraction; RAAS, renin-angiotensin-aldosterone system.

the clinician to improve the prognosis of patients with chronic HF and LV systolic dysfunction by using candesartan.

\section{Disclosures}

The authors have no conflicts of interest to disclose.

\section{References}

1. Levy D, Kenchaiah S, Larson MG, et al. Long-term trends in the incidence of and survival with heart failure. N Engl J Med. 2002;347:1397-402.

2. Stewart S, MacIntyre K, Capewell S, et al. Heart failure and the aging population: an increasing burden in the 21 st century? Heart. 2003;89:49-53.

3. Redfield MM. Heart failure - an epidemic of uncertain proportions. N Engl J Med. 2002;347:1442-1444.

4. European Study Group on Diastolic Heart Failure. How to diagnose diastolic heart failure. Eur Heart J. 1998;19:990-1003.

5. Jessup M, Brozena S. Heart failure. N Engl J Med. 2003;348:2007-2018.

6. Dickstein K, Cohen-Solal A, Filippatos G, et al. ESC Guidelines for the diagnosis and treatment of acute and chronic heart failure 2008: the Task Force for the Diagnosis and Treatment of Acute and Chronic Heart Failure 2008 of the European Society of Cardiology. Developed in collaboration with the Heart Failure Association of the ESC (HFA) and endorsed by the European Society of Intensive Care Medicine (ESICM). Eur Heart J. 2008;29:2388-2442.

7. Packer M, Fowler MB, Roecker EB, et al. Carvedilol Prospective Randomized Cumulative Survival (COPERNICUS) Study Group. Effect of carvedilol on the morbidity of patients with severe chronic heart failure: results of the carvedilol prospective randomized cumulative survival (COPERNICUS) study. Circulation. 2002;106:2194-2199.

8. CIBIS-II Investigators and Committees. The Cardiac Insufficiency Bisoprolol Study II (CIBIS-II): a randomised trial. Lancet. 1999; 353:9-13.

9. MERIT-HF Study Group. Effect of metoprolol CR/XL in chronic heart failure: Metoprolol CR/XL Randomised Intervention Trial in Congestive Heart Failure (MERIT-HF). Lancet. 1999;353:2001-2007.

10. The CONSENSUS Trial Study Group. Effects of enalapril on mortality in severe congestive heart failure. Results of the Cooperative North Scandinavian Enalapril Survival Study (CONSENSUS). NEngl J Med. 1987;316:1429-1435.

11. The SOLVD Investigators. Effect of enalapril on survival in patients with reduced left ventricular ejection fractions and congestive heart failure. N Engl J Med. 1991;325:293-302.
12. Garg R, Yusuf S. Overview of randomized trials of angiotensinconverting enzyme inhibitors on mortality and morbidity in patients with heart failure. Collaborative Group on ACE Inhibitor Trials. JAMA. 1995;273:1450-1456.

13. Pitt B, Zannad F, Remme WJ, et al. Randomized Aldactone Evaluation Study Investigators. The effect of spironolactone on morbidity and mortality in patients with severe heart failure. $N$ Engl J Med. 1999;341:709-717.

14. Pitt B, Remme W, Zannad F, et al. Eplerenone Post-Acute Myocardial Infarction Heart Failure Efficacy and Survival Study Investigators. Eplerenone, a selective aldosterone blocker, in patients with left ventricular dysfunction after myocardial infarction. $N$ Engl J Med. 2003;348:1309-1321.

15. Lewis EJ, Hunsicker LG, Clarke WR, et al; Collaborative Study Group. Renoprotective effect of the angiotensin-receptor antagonist irbesartan in patients with nephropathy due to type 2 diabetes. $N$ Engl J Med. 2001;345:851-860.

16. Brenner BM, Cooper ME, de Zeeuw D, et al. RENAAL Study Investigators. Effects of losartan on renal and cardiovascular outcomes in patients with type 2 diabetes and nephropathy. $N$ Engl J Med. 2001;345:861-869.

17. Dahlöf B, Devereux RB, Kjeldsen SE, et al. LIFE Study Group. Cardiovascular morbidity and mortality in the Losartan Intervention For Endpoint reduction in hypertension study (LIFE): a randomised trial against atenolol. Lancet. 2002;359:995-1003.

18. Lithell H, Hansson L, Skoog I, et al. SCOPE Study Group. The Study on Cognition and Prognosis in the Elderly (SCOPE): principal results of a randomized double-blind intervention trial. J Hypertens. 2003;21:875-886.

19. Pitt B, Segal R, Martinez FA, et al. Randomised trial of losartan versus captopril in patients over 65 with heart failure (Evaluation of Losartan in the Elderly Study, ELITE). Lancet. 1997;349:747-752.

20. Pitt B, Poole-Wilson PA, Segal R, et al. Effect of losartan compared with captopril on mortality in patients with symptomatic heart failure: randomised trial - the Losartan Heart Failure Survival Study ELITE II. Lancet. 2000;355:1582-1587.

21. Cohn JN, Tognoni G. Valsartan Heart Failure Trial Investigators. A randomized trial of the angiotensin-receptor blocker valsartan in chronic heart failure. N Engl J Med. 2001;345:1667-1675.

22. Pfeffer MA, Braunwald E, Moyé LA, et al. Effect of captopril on mortality and morbidity in patients with left ventricular dysfunction after myocardial infarction. Results of the survival and ventricular enlargement trial. The SAVE Investigators. N Engl J Med. 1992;327:669-677.

23. Swedberg K, Held P, Kjekshus J, et al. Effects of the early administration of enalapril on mortality in patients with acute myocardial infarction. Results of the Cooperative New Scandinavian Enalapril Survival Study II (CONSENSUS II). N Engl J Med. 1992;327:678-684.

24. Flather MD, Yusuf S, Køber L, et al. Long-term ACE-inhibitor therapy in patients with heart failure or left-ventricular dysfunction: a systematic overview of data from individual patients. ACE-Inhibitor Myocardial Infarction Collaborative Group. Lancet. 2000;355:1575-1581.

25. Pfeffer MA, McMurray JJ, Velazquez EJ, et al. Valsartan in Acute Myocardial Infarction Trial Investigators. Valsartan, captopril, or both in myocardial infarction complicated by heart failure, left ventricular dysfunction, or both. N Engl J Med. 2003;349:1893-1906.

26. Yusuf S, Pfeffer MA, Swedberg K, et al. CHARM Investigators and Committees. Effects of candesartan in patients with chronic heart failure and preserved left-ventricular ejection fraction: the CHARM-Preserved Trial. Lancet. 2003;362:777-781.

27. Massie BM, Carson PE, McMurray JJ, et al. The I-PRESERVE Investigators. 2008. Irbesartan in Patients with Heart Failure and Preserved Ejection Fraction. $N$ Engl J Med. 2008;359:2456-2467.

28. Nishikawa K, Naka T, Chatani F, et al. Candesartan cilexetil: a review of its preclinical pharmacology. J Hum Hypertens. 1997;11(Suppl 2):S9-S17.

29. Meredith PA. Candesartan cilexetil - a review of effects on cardiovascular complications in hypertension and chronic heart failure. Curr Med Res Opin. 2007;23:1693-1705. 
30. Sakata Y, Yamamoto K, Mano T, et al. Angiotensin II type 1 receptor blockade prevents diastolic heart failure through modulation of $\mathrm{Ca}(2+)$ regulatory proteins and extracellular matrix. J Hypertens. 2003;21:1737-1745.

31. McKelvie RS, Yusuf S, Pericak D, et al. Comparison of candesartan, enalapril, and their combination in congestive heart failure: randomized evaluation of strategies for left ventricular dysfunction (RESOLVD) pilot study. The RESOLVD Pilot Study Investigators. Circulation. 1999;100:1056-1064.

32. McKelvie RS, Rouleau JL, White M, et al. Comparative impact of enalapril, candesartan or metoprolol alone or in combination on ventricular remodelling in patients with congestive heart failure. Eur Heart J. 2003;24:1727-1734.

33. McMurray JJ, Ostergren J, Swedberg K, et al. CHARM Investigators and Committees. Effects of candesartan in patients with chronic heart failure and reduced left-ventricular systolic function taking angiotensin-converting-enzyme inhibitors: the CHARM-Added trial. Lancet. 2003;362:767-771.

34. White M, Lepage S, Lavoie J, et al. Effects of combined candesartan and $\mathrm{ACE}$ inhibitors on BNP, markers of inflammation and oxidative stress, and glucose regulation in patients with symptomatic heart failure. J Card Fail. 2007;13:86-94.

35. Granger CB, McMurray JJ, Yusuf S, et al; CHARM Investigators and Committees. Effects of candesartan in patients with chronic heart failure and reduced left-ventricular systolic function intolerant to angiotensinconverting-enzyme inhibitors: the CHARM-Alternative trial. Lancet. 2003;362:772-776.

36. Young JB, Dunlap ME, Pfeffer MA, et al. Candesartan in Heart failure Assessment of Reduction in Mortality and morbidity (CHARM) Investigators and Committees. Mortality and morbidity reduction with Candesartan in patients with chronic heart failure and left ventricular systolic dysfunction: results of the CHARM low-left ventricular ejection fraction trials. Circulation. 2004;110:2618-2626.

37. Dagenais GR, Pogue J, Fox K, et al. Angiotensin-converting-enzyme inhibitors in stable vascular disease without left ventricular systolic dysfunction or heart failure: a combined analysis of three trials. Lancet. 2006;368:581-588.

38. Demers C, McMurray JJ, Swedberg K, et al. CHARM Investigators. Impact of candesartan on nonfatal myocardial infarction and cardiovascular death in patients with heart failure. JAMA. 2005;294:1794-1798.

39. Maggioni AP, Latini R, Carson PE, et al; Val-HeFT Investigators. Valsartan reduces the incidence of atrial fibrillation in patients with heart failure: results from the Valsartan Heart Failure Trial (Val-HeFT). Am Heart J. 2005;149:548-557.
40. Ducharme A, Swedberg K, Pfeffer MA, et al; CHARM Investigators. Prevention of atrial fibrillation in patients with symptomatic chronic heart failure by candesartan in the Candesartan in Heart failure: Assessment of Reduction in Mortality and morbidity (CHARM) program. Am Heart J. 2006;152:86-92.

41. Poornima IG, Parikh P, Shannon RP. Diabetic cardiomyopathy: the search for a unifying hypothesis. Circ Res. 2006;98:596-605.

42. Julius S, Kjeldsen SE, Weber M, et al; VALUE trial group. Outcomes in hypertensive patients at high cardiovascular risk treated with regimens based on valsartan or amlodipine: the VALUE randomised trial. Lancet. 2004;363:2022-2031.

43. Abuissa H, Jones PG, Marso SP, et al. Angiotensin-converting enzyme inhibitors or angiotensin receptor blockers for prevention of type 2 diabetes: a meta-analysis of randomized clinical trials. $J \mathrm{Am}$ Coll Cardiol. 2005;46:821-826.

44. Andraws R, Brown DL. Effect of inhibition of the renin-angiotensin system on development of type 2 diabetes mellitus (meta-analysis of randomized trials). Am J Cardiol. 2007;99:1006-1012.

45. Yusuf S, Ostergren JB, Gerstein HC, et al. Candesartan in Heart Failure-Assessment of Reduction in Mortality and Morbidity Program Investigators. Effects of candesartan on the development of a new diagnosis of diabetes mellitus in patients with heart failure. Circulation. 2005;112:48-53.

46. Anand IS, Latini R, Florea VG, et al. Val-HeFT Investigators. C-reactive protein in heart failure: prognostic value and the effect of valsartan. Circulation. 2005;112:1428-1434.

47. O'Meara E, Solomon S, McMurray J, et al. Effect of candesartan on New York Heart Association functional class. Results of the Candesartan in Heart failure: Assessment of Reduction in Mortality and morbidity (CHARM) programme. Eur Heart J. 2004;25:1920-1926.

48. Desai AS, Swedberg K, McMurray JJ, et al; CHARM Program Investigators. Incidence and predictors of hyperkalemia in patients with heart failure: an analysis of the CHARM Program. $J$ Am Coll Cardiol. 2007;50:1959-1966.

49. Weir RA, McMurray JJ, Puu M, et al; CHARM Investigators. Efficacy and tolerability of adding an angiotensin receptor blocker in patients with heart failure already receiving an angiotensin-converting inhibitor plus aldosterone antagonist, with or without a beta blocker. Findings from the Candesartan in Heart failure: Assessment of Reduction in Mortality and morbidity (CHARM)-Added trial. Eur J Heart Fail. 2008;10:157-163.

50. Cohen-Solal A, McMurray JJ, Swedberg K, et al; For the CHARM Investigators. Benefits and safety of candesartan treatment in heart failure are independent of age: insights from the Candesartan in Heart failure Assessment of Reduction in Mortality and morbidity programme. Eur Heart J. 2008;29:3022-3028. 